\title{
UNDERSTANDING TEXT AS SOCIAL PRACTICE: AN EXPLORATION OF THE POTENTIAL OF SYSTEMIC FUNCTIONAL GRAMMAR TO FACILITATE STUDENTS' INTERPRETATION OF MEDIA TEXTS.
}

Jenny Clarence-Fincham

University of Natal

It has frequently been claimed that Halliday's Systemic Functional Grammar (SFG) is a powerful linguistic tool which facilitates analytical and interpretative skills and provides a flexible, yet structured set of analytical tools with which to interpret texts. With this claim as a backdrop, this article asks whether SFG is, in fact an appropriate analytical approach for under-graduate students and whether it can facilitate their ability to analyse texts. Its context is a second level course, Analysing Media Texts, offered at Natal University. Broadly framed by critical discourse analysis, it traces the development of a thirteen week module and, using student analyses for illustrative purposes, identifies pedagogical challenges and difficulties that need to be confronted before any strong claims can be made. It is concluded that, on the evidence of students' responses to texts analysed during this course, it is not yet possible to make strong claims about the benefits of SFG. There is enough positive evidence, however, to pursue the possibility that with innovative curriculum development and the careful scaffolding and integration of concepts, SFG will be clearly shown to have an extremely important role to play.

Daar is dikwels beweer dat Halliday se Sistemies-Funksionele Grammatika (SFG) 'n kragtige linguistiese middel is wat analitiese en interpreterende vaardighede bevorder en 'n plooibare, dog gestruktureere stel analitiese gereedskap verskaf waarmee tekste geïnterpreteer kan word. Met dié bewering as agtergrond vra hierdie artikel of SFG inderdaad ' $n$ toepaslike analitiese benadering vir voorgraadse studente is en of dit hulle vermoë om tekste te ontleed, bevorder. Die konteks is 'n tweedejaarskursus, Analysing Media Texts, wat aan die Universiteit van Natal aangebied word. Breedweg omraam deur kritiese diskoersanalise, speur die artikel die ontwikkeling van 'n module van dertien weke $n a$, met gebruik van studenteontledings ter illustrasie en identifiseer pedagogiese uitdagings en probleme wat aangespreek moet word voordat enige sterk aansprake gemaak kan word. Daar word tot die slotsom gekom, op grond van die studente se reaksies op tekste wat gedurende hierdie kursus ontleed is, dat dit nog nie moontlik is om sterk aansprake oor die voordele van SFG te maak nie. Daar is egter genoeg positiewe bewyse om die moontlikheid op te volg dat met vernuwende kurrikulumontwikkeling en die versigtige ondersteuning en integrering van konsepte duidelik bewys sal kan word dat SFG 'n uiters belangrike rol te speel het. 
The immediate pedagogical context for this article is a thirteen week, second level module in Applied Language Studies which is offered at Natal University on the Pietermaritzburg campus. Entitled Analysing Media Texts, this module links systemic functional grammar (SFG) and critical discourse analysis (CDA) to form a theoretical framework for the analysis of texts drawn from newspapers, magazines and advertisements. Its broad aim is to introduce students to the key principles of CDA and to Halliday's SFG as a system which is integrally related to social practice and to show how these can assist them to understand the social and constructed nature of discourses, especialiy those typically found in media texts.

\section{THEORETICAL FRAMEWORK: CRITICAL DISCOURSE ANALYSIS AND OF SYSTEMIC FUNCTIONAL GRAMMAR}

The broad theoretical framework for this course is CDA. Although analysts reveal different emphases, they are all concerned with moving beyond linguistic description to explanation which shows how social inequalities are reflected and constructed in and through language. Another shared goal is to find ways through their work to challenge and to change the conditions of inequality that their work uncovers (Pennycook, 1995). This shared perspective revolves around the key concept of language as discourse or 'social practice' (Fairclough, 1989: 1), the fact that language practice is socially determined; it is a social act in itself which is in turn shaped by broader social and ideological conditions (Chouliaraki \& Fairclough, 1999; Fairclough 1989, 1992, 1995; Fairclough \& Wodak, 1997; Fiske, 1994; Gee, 1996; Kress, 1985; Mills, 1997; Pennycook, 1994, 1995; van Dijk, 1997). This notion of discourse challenges the possibility of autonomous subjects and ideologically neutral language use. Rather, human beings are viewed as socialised subjects whose subjectivities and language use are constructed within particular social and cultural discourses (Pennycook, 1995). Language, which always contains traces of its social history is what Fiske calls 'politicized, power-bearing language, employed to extend or defend the interests of its discursive community' (1994: 3). Discourses comprise complex, historically-based ways of constructing knowledge, social practices, subjectivity and the power relations which are implicit in these knowledges. Within this perspective, texts are viewed as social products and human subjects, because they have differential access to social, educational and political experiences, are differentially positioned in various social contexts.

The version of CDA referred to here is most frequently associated with the work of Fairclough who argues, with Chouliaraki, that CDA should be seen, not as a particular theory but rather as 'one contributory element in research on social practices' (1999:16). The primary aim of CDA is to uncover and understand naturalised ideological representations which have come to be viewed as common-sense social practice and to elucidate and clarify the social effects of such practices. Practically, this means investigating verbal interactions with an eye to how they are shaped by, and how they shape, social structures (Fairclough, 1995c).

Fairclough has developed a three dimensional model for CDA, $(1989,1992,1995 \mathrm{c})$ which comprises three interrelated domains, the descriptive, the interpretive and the explanatory (see Figure1). 


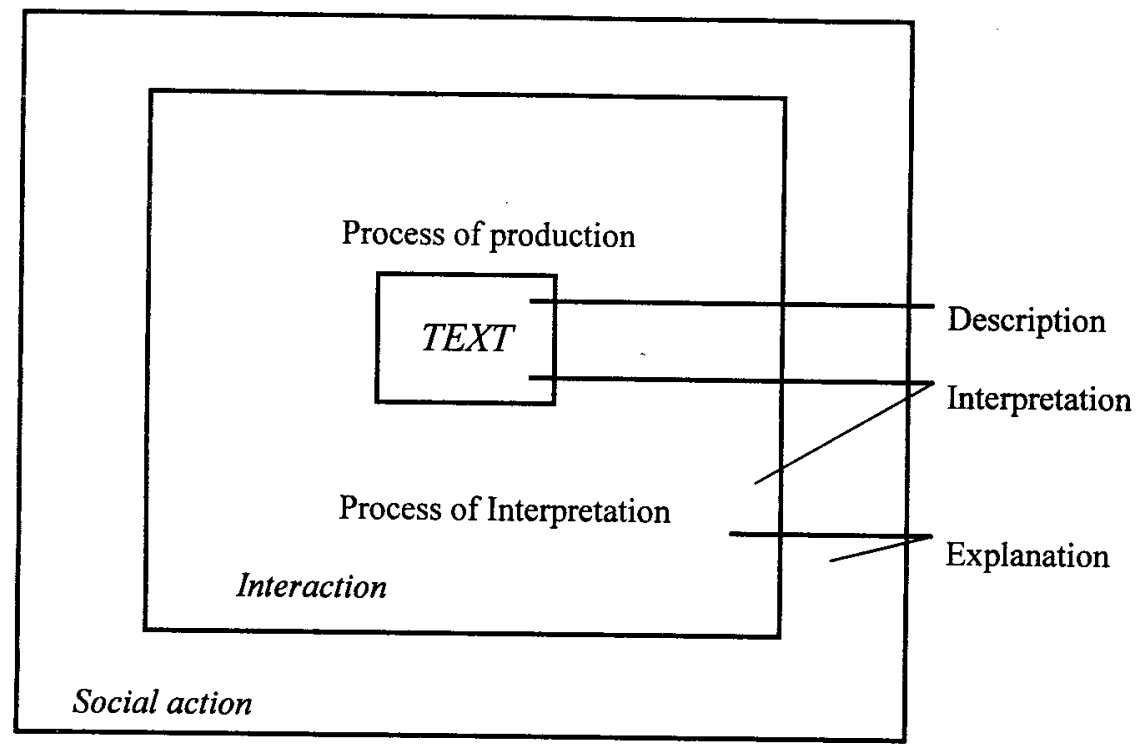

Figure 1 : A three dimensional view of discourse analysis. (Fairclough 1989)

The descriptive domain entails close textual and linguistic analysis involving both the traditional levels of analysis in terms of phonology, vocabulary, syntax and semantics and analysis of textual organisation in a broader sense which includes the sequencing of information and intersentential cohesion. Drawing on the work of Halliday $(1978 ; 1985)$ Fairclough links this textual domain with ideational meaning which revolves around the way in which the world is represented.

The interpretive process is primarily concerned with the production and interpretation of texts as they emerge in specific social contexts. It is viewed as a dialectical interplay between various features of texts and what Fairclough terms 'members' resources' (1989: 11) which refer to socially constructed resources which are used by subjects to produce and interpret text. Interpretation entails a complex interplay between different domains which includes the ability to interpret both situational and intertextual contexts in conjunction with knowledge of the linguistic system, semantic representations, pragmatic conventions, the ability to establish connections within and between utterances and recognition of various generic structures.

The explanatory dimension foregrounds the relationship between the interaction between the productive and interpretive processes and the broad social context and represents discourse as a social practice which is shaped by social structures and which can sustain or change those structures (Fairclough, 1989). In understanding any text and the discourse of which it is part, the explanatory dimension explores which power relations, at situational, institutional and social levels contribute towards the shaping of the discourse. It also entails a consideration of how a discourse is positioned in relation to social contexts at each of these three levels and to what extent it contributes to or transforms existing power relations.

Using this model, Fairclough has formulated guidelines for the analysis of media texts (1995a). The questions below are based on these guidelines and were used by my students as they considered newspaper reports, editorials, feature articles and advertisements. 
(a) How are wider social changes represented in the media? (eg race and gender relations)

(b) How does this text represent present social conditions? Is it attempting to change social reality in any way? How?

(c) Would the same text have been produced thirty years ago? What changes have occurred in that time?

(d) Who produced this text? Why was it produced? What it the relationship between the producers and the interpreters of this text? How is this relationship realised linguistically?

(e) How may different discourses can be identified in the text? How do the different discourses relate to each other?

(f) How many genres are evident in this text? Which linguistic structures are typical of this genre?

(g) How is the world represented in the text? What linguistic choices (eg lexical items, transitivity, cohesive devices) are evident in it? Are there any pictures? What is the relationship between the verbal and visual aspects of the text? What effect does each aspect of the text have on the meaning as a whole?

(h) How are the different linguistic metafunctions (i.e. ideational, interpersonal and textual) realised in this text?

In the early stages of the course, students were introduced gradually to each of these questions as they broadened their knowledge of Fairclough's model. Questions a-c, for example, were specifically linked to the explanatory domain while question (d) was discussed in relation to the interpretive stage. Question (e) was linked to both the explanatory and the interpretive domains while the remainder of the questions (f-h) fall within the descriptive dimension. It should be noted here that although these stages were dealt with in a somewhat 'linear' fashion in the classroom, moving inwards from the broad social context to detailed linguistic analysis, the interrelatedness of the dimensions and the fact that the process can begin at any point on the model (Janks, 1997) was constantly pointed out to students.

It has long been recognised that Halliday's SFG is the major linguistic theory most compatible with a critical approach to discourse. It has been appropriated by many linguists (most notably by groups in East Anglia and in Australia and also, for example, by Chouliaraki \& Fairclough, 1999; Clark \& Ivanic, 1997; Fairclough, 1992, 1995a and b ; Janks, 1996; Kress, 1985) as the main resource for textual analysis precisely because it provides the potential for a critical interpretation of linguistic expressions within a variety of discourses. Certainly, in addressing each of Fairclough's questions, SFG provided additional and enriching analytical tools with which to analyse text. The remainder of this section will explain key Hallidayan concepts, show how students were introduced to them and how they were linked to CDA.

As his point of departure Halliday argues that 'language is as it is because of the functions it has evolved to serve in people's lives ... In order to understand linguistic structures in 
functional terms, we have to proceed from the outside inwards, interpreting language by reference to its place in the social process' (1978: 4). Briefly, Halliday argues that a language is interpreted as a system of meaning potential, accompanied by forms through which the meanings can be realised. He defines systemic theory as 'a theory of meaning as choice, by which a language, or any other semiotic system, is interpreted as networks of interlocking options' (1985: xiv). Functional linguistics, then, foregrounds linguistic choice and treats structures as derivable from the choices made via realisation rules: "the relation between the semantics and the grammar is one of realisation: the word 'realises', or encodes, the meaning. The wording, in turn, is 'realised by' sound or writing' (Halliday, 1985: $\mathrm{xx}$ ). This concept of realisation enables Halliday to attempt an explanation of the relationship between text and context and to show how what he calls context of culture links to the immediate context of situation (the field, tenor and mode of discourse) and how this in turn is realised by the metafunctions of language (the ideational, the interpersonal and the textual) in the broader sociohistorical context.

For Halliday, a text, in the broadest terms, is 'language that is functional' (Halliday \& Hasan, 1989: 10), that is any language, written or spoken, which has social meaning in a particular, concrete, situation. Crucially, he views text as a semantic unit, an intersection of potential meanings, rather than a combination of words and sentences, and argues that it needs to be considered from two perspectives simultaneously, from the notion of text as product and of text as process. It is a product in that it is a linguistic structure which can be studied. At the same time it is a process 'in the sense of a continuous process of semantic choice, a movement through the network of meaning potential, with each set of choices constituting the environment for a further set' (Halliday \& Hasan, 1989: 10). So a text is both structured and structuring; it draws on and exemplifies the linguistic system but is simultaneously located in specific and potentially new social contexts. It is 'an instance of social meaning in a particular context of situation' (Halliday \& Hasan, 1989: 11). As such, all texts are 'channels for socially driven changes in the language system' (Chouliaraki \& Fairclough, 1999: 141), and all texts open up the linguistic system to new contextual possibilities.

Halliday has developed a conceptual framework which he claims facilitates the understanding of the production and interpretation of text, and helps to capture the elusive relation between language and social structure. His point of departure is that the construction of a text is neither random nor mechanical, but is systematically related to both its social environment and the functional organisation of its language. A central question for him revolves around the ways in which individual texts interact with and relate to their social contexts.

Halliday begins by defining a text's outer framework or context of culture. This refers to the extralinguistic features of the text, the culturally-based conventions or 'the sum of all the meanings it is possible to mean in that particular culture' (Butt, 2000: 3). There is no explicit analysis of power relations here but a consideration of cultural variables (which includes anything from religious affiliation and beliefs about gender relationships to gesture, intonation and modes of address) easily leads to such an analysis.

Within this broad context, Halliday places what he calls the context of situation. This is the immediate social context of a text which consists of three features which 'serve to interpret the social context of the text, the environment in which meanings are being exchanged' (Halliday \& Hasan, 1989: 12). The first of these is the 'field of discourse' which refers to the 
type of social action being depicted in the text, what is going on. This social feature is realised at a linguistic/semantic level as the experiential metafunction, which involves an understanding of 'the processes being referred to, the participants in these processes, and the circumstances - time, cause, etc. associated with them' (Halliday \& Hasan, 1989: 45). The central linguistic features which realise this function are lexicalisation, transitivity and voice.

The second feature of the context of situation is the 'tenor of discourse' which refers to the relationship between the participants in the text, their statuses and roles, the permanent or temporary nature of these relationships and the types of speech roles they are assuming in the dialogue. This also includes the speaker's/writer's attitudes towards the subject matter. Linguistically, it is realised as the interpersonal function of language and is characterised by systems of mood and modality in conjunction with lexical choice.

The third characteristic of the context of situation is the 'mode of discourse' which Halliday describes as referring to the function of the language of the text which includes its organisation, its channel and its status. For Halliday, the textual component has what he calls 'an enabling function' (1978: 113). It is only through the textual mode of discourse that ideational and interpersonal meanings are realised. The key linguistic features here are cohesion and coherence, and information structure. It is the combination of context of culture and context of situation which allows fruitful comparison between one text and another.

In the context of this course, students were introduced gradually to the Hallidayan concepts of context of culture, context of situation, experiential, interpersonal and textual meaning and with each concept, a link to the Fairclough model was made. Context of culture, for example, was closely linked to the explanatory domain, (and hence questions 1-3) but was not seen as synonymous with it. The situational components of situation of context and the linguistic realisations of each, were gradually introduced with field of discourse and experiential meaning linked to questions (e), (g) and (h), tenor and interpersonal meaning to (d) and (h) and mode and textual meaning to $(\mathrm{e}),(\mathrm{g})$ and $(\mathrm{h})$.

\section{TRANSLATING THEORY INTO PRACTICE}

The translation of these theoretical perspectives into clear and systematic classroom practice presents many challenges. This section includes a brief summary of the intended outcomes of this course, the range of topics covered and then, drawing on student responses to texts, considers some aspects of the course in more detail.

The outcomes for the course were that, by completion of the module, learners should be able to understand and apply the broad principles of CDA, to identify the key tenets of Hallidayan grammar, particularly the contextual features of field, tenor and mode and to understand how these are linguistically realised as experiential, interpersonal and textual metafunctions, especially in relation to media texts. Within this, they would also use critical linguistics as a method of textual analysis and draw on the notion of genre. It was acknowledged that systemic functional grammar is a complex and abstract linguistic theory and the students were not likely to move beyond a 'rough" rather than a 'fine-tuned' analysis of texts. It was also acknowledged that many media texts would be too complex for student analysis and would need to be carefully chosen.

As already indicated, the course began with an introduction to CDA - using texts drawn from 
newspapers and magazines, students generated questions which they considered necessary in order to analyse a text and were then introduced to various perspectives on discourse (Foucault, 1970; Kress, 1985; Mills, 1997; Fiske, 1994 and Fairclough, 1989, 1995a, 1995b) and to Fairclough's three dimensional model. This was followed by a specific focus on media discourse which involved introducing students to ideas about genre (Bhatia, 1993), mythology, signs, text, intertextuality, anchorage, interpellation and ideology (Kress \& van Leeuwen, 1996, Tolson, 1996).

Students were then introduced to key Hallidayan concepts relating to grammar and meaning, linguistic choice, the role of context and text in context. The introduction of context of culture, context of situation (and the related linguistic metafunctions), was a pivotal point in the course because it was here that a careful mapping of Fairclough's and Halliday's categories was necessary so that students could link and synthesise the two models while at the same time retaining a clear sense of each. Once this had been established, the linguistic systems linked to each of the three metafunctions were dealt with.

\section{STUDENT INTERPRETATION OF TEXTS}

Students gradually built a functional metalanguage as they were introduced to the linguistic systems of Transitivity, Mood, Modality and Information Structure, and they used this in their analyses, first of individual sentences and then of a range of media texts. Even given the careful selection of relatively simple media texts, the transition from sentence to report or editorial was often difficult. However, these difficulties had a positive spin-off in that they provided opportunities for students to consider, for example, the difficulties that can arise when attempting to identify Process Types. They also discovered that if they approached a text holistically rather than becoming intimidated by complex embedded clauses, they knew a lot more than seemed apparent at first.

The three texts below (see appendix A for Texts $A$ and $B$ ) are examples of some of the texts analysed by students. The first two is an extracts from a feature article (analysed as a unseen text in the exam) and the second is a newspaper report (a seen text analysed in the same exam), while the third is an example of a student-generated text. Text $A$ was chosen because it lends itself particularly well to the analysis of Transitivity and to the effects of the switch of Process Types (in conjunction with lexical choices) on the representation of the atmosphere of the scene. It is also an appropriate and accessible choice of unseen text for an exam in that it is structurally simple. Students were required to analyse it in terms of its experiential, interpersonal and textual meanings and were then asked to comment specifically on how the use of different Process types and Participant roles contribute to the changing atmosphere. Text $B$ was also chosen bearing simple sentence structure in mind and because of its interest value and recent appearance in the local press.

Extracts 1-3, which are responses to Text $A$, include students' linguistic and conceptual errors. 


\section{Extract 1}

With regards to its Experiential meaning, the first paragraph of this text succeeds in creating a believable context of situation for the reader. With regard to field, this . . . is realised by the extensive use of Relational, eg 'it's cold' and 'people are just pools of headlamp lights' and existential processes. ... From an Interpersonal perspective, the paragraph employs extensive use of finite verb 'is' in the present tense, which contributes to a sense of immediacy and authority in the recount narrative. The fact that the actors are all in subject positions also gives a sense of reality. With regard to the textual metafunctions, the use of a variety of topical themes helps to build up a descriptive and varied picture of reality 'now; alight wind; it's; really deep; people'

In the second paragraph the greater use of behavioral and material Processes 'parted; reared; whooped; crumpled and gasping, together with more qualifiers (slowly; promptly) helps to realised the field of this piece. From an interpersonal perspective, this paragraph does not contain any passive sentences and, like the first paragraph, the predominance of declarative sentences with positive polarity, works together to realised the tenor of the text which is a reliable and trustworthy author recounting his/her experience. From a textual perspective this text is cohesive even though there is not a strict Theme A, Rhyme A; Theme B/RhemeB progression. The use of cohesive devices such as 'then' helps to achieve this.

In the first paragraph, the mainly existential processes work to create a rather tense atmosphere. It is the setting for the action that follows in paragraph two. This makes sense because when wanting to set the scene, it is not necessary to have actors and goals. On the other hand, in paragraph two it is essential that there are more material processes and actors as without them, there could be no action in the story.

This analysis falls within the 'rough tuned' expectation mentioned earlier. It cannot be claimed that it is a sophisticated complex analysis but is does provide an example of an analysis in which a student has managed to come to grips with basic Hallidayan concepts and is beginning to apply them appropriately to the text. Despite the absence of necessary capitalisation, some confusion between relational and existential processes (for example 'It's cold' is categorised as relational rather than existential) and the simplistic categorisation of Verbal Groups as Process types, she produces a well structured, generally accurate answer which fulfils the requirements of the question without attempting to analyse every clause. Throughout, she uses the metalanguage relatively flexibly, making appropriate mention of each of the three metafunctions and she shows how the choice of Process type and Participant role functions to construct the different sections of the text. She does not, however, link this to key lexical choices made to represent the tense atmosphere.

Here, for comparison, are two further examples: 


\section{Extract 2}

The passage is highly descriptive as it makes use of Attributive processes to create metaphors of imagery. There is very little evidence of material Processes most of what is being described is sensual, described in flowing sentences, littered with conjunctions. The first paragraph is written in the present in order to describe the abstract sensual events within the text. The second paragraph slips into the past tense, becoming a narrative recount. In the first paragraph, the process are mostly Visual or Mental and very little effort is made to identify any participants in order for the reader to imagine him/herself. The second paragraph readily identifies participants and material processes in order to add action to the recount.

This student takes a far more general and less rigorous approach to the text and although he reveals a smattering of SFG metalanguage (Attributive and Mental processes, for example), his analysis is often vague. His answer is devoid of specific examples and excludes any discussion of interpersonal or textual meaning. His analysis of experiential meaning, however, broadly captures the effects of the changing Process types as the text develops. However, it also includes a new transitivity category (Visual) and an intriguing substitution of conjunctions for adjectives.

\section{Extract 3}

Experiential meanings refer to how the language encodes our experiences of the world and creates a picture of what is going on - that is it creates experiential meaning. In terms of the chosen text, we can see that the words (verbal groups) chosen construct a picture of reality, for example, words such as 'solitary', 'screamed' and 'gasping'. The words help us to follow the experiences of the text. . . . The experiential processes, interpersonal processes all work together and bring cohesion to the text with the important use of participant roles.

This student, who did extremely well in the exam in both the production and the interpretation of sentences, could produce nothing more than previously learnt definitions about the three linguistic metafunctions. Although she showed the ability to apply her insights to text in the classroom, under exam conditions her confidence deserts her and she shows little capacity for the necessary application of general principles. The final sentence here indicates most forcefully that she has very little insight into the function of the various Process types.

In general, student analyses of this text revealed a tendency towards vague definitions which were produced with insufficient reference to the text in question. When they did attempt to analyse specific Process types, there was often confusion, for example, between Relational and Existential Processes. While some students managed to identify the function of the changing Process types and the related Participant roles, a few were completely unable to recognise this. In terms of interpersonal meaning, students referred to the construction of interpersonal relationships but failed to identify the declarative mood of the text or the SFPCA functions. In addition, the modality of the text was largely ignored and there was a notable absence of reference to textual meaning. 
With Text $B$, students were required to produce a more holistic, critical analysis and asked to respond to this question: Drawing on Fairclough's three dimensional model, your knowledge of critical linguistics and of functional grammar, analyse the text below. Below is a cross section of the answers provided.

\section{Extract 4}

The text contains mostly material processes. This is because of the situation that was happening. A lot of action is involved... Violent action is involved in the text as students are marching. The reader of this text might be the students themselves, the parents, the lecturers and the head of the varsity. The language that is used here involves violence so it is representing or positioning the students as violent. The situational relations shape the text. . The choice of words expresses the situation as it was, words like 'disrupted', 'toppled' and 'damaged' all contribute in positioning the students as violent. This positioning relates to Fairclough's interpretive box and it is the same as the interpersonal meaning. The tense that is used is the past tense throughout the text because this is a report.

\section{Extract 5}

\section{Conditions of production and reception}

This text is shaped by the institutional discourse order of staff student relationships. It is further structured in a context of an unequal power relationship in terms of institutionalized authority, as the management of the university are traditionally more powerful than the students. It is also possible that . . . it is influenced by racist discourse with management being traditionally white and these students, black. .

\section{Processes of production and reception}

This news report, ostensibly written objectively is a discourse order of the discourse of newsreporting and journalism. As such, it acts as an interface, a mediator between the multiplicity of discourses in the country and the multiplicity of readers, each of whom will interpret the text according to the constraints of their identities and subject positions. . I I would like to suggest that the ideal reader is one who is sympathetic with the authoritarian structures . . . this is based on the underlying assumption that the students 'damage, topple and disrupt' while the management uphold the right of protest while maintaining law and order. .

Text

The first positioning of the first sentence of the report is significant, as not only does it link back to the headline, but it also centres the reader's attention on the protest itself. The fact that the language is arranged so that 'student' becomes an adjective or epithet modifying 'process' instead of an active agent serves to objectify the student action... 


\section{Extract 6}

The most notable aspect of this text is the perceived power attributes of the people within the text. The students are represented as unruly and unproductive - 'toyi-toyied and held meetings' while UDW management remain calm and collected brushing off the unruly students with the academic programme will continue normally'. . . the plight of the students is mentioned but its representation is unnamed, unlike the UDW management who is named and quoted.

Although each of these extracts exhibits at least some analytical potential, what is immediately striking about them all (especially viewed together) is the absence of any detailed Hallidayan analysis. When asked about this, the authors of extracts 4 and 6 indicated that they had lacked the confidence to attempt a Hallidayan analysis and deliberately avoided it, opting instead to draw on a more general knowledge of CDA and critical linguistics, most particularly the way in which lexical choice functions to position participants in the text. The author of extract 5 said that she had focused her attention on Fairclough in the interests of time and also because she had just completed a detailed Hallidayan analysis. (see Extract 1). She produces a systematic analysis of the text, drawing primarily on Fairclough's model and making only a few passing references to Halliday. Whatever their reasons, the fact remains that, with the exception of Extract 4, which makes an explicit connection between Fairclough's interpretive domain and Halliday's interpersonal meaning, none of the students attempts even cursory links between the two models. In Extracts 4 and 6, however, there are links made between the text and the generic form to which it belongs.

\section{STUDENTS' PRODUCTION OF TEXT}

While students were involved primarily in the interpretation of texts, there was one activity during the course when they produced an advertisement of their choice. They worked in groups of three, chose their product, constructed an advert and than handed it to another group for analysis and comment. During the final discussion, each group was expected to explain and justify the linguistic choices they had made with reference to CDA and SFG. This expectation resulted in extensive debate and argument as options were eliminated and choices negotiated. During the course of discussion, I was able to listen to, monitor and record student observations and decisions. The text below is the end point of one process which proved not only enjoyable for students but also extremely beneficial. Accompanied by an illustration of a rather bored looking woman patting an alarmed superman on the head, the text read

\footnotetext{
We've highjacked their razors

We've stolen their cologne

NOW it's time to get into

their SHORTS

BETTY BOXERS

The revolutionary range of feminine

boxers for women who aren't afraid

to cross the boundary into a MAN'S

world. Available in a wide range of
} 
colours and styles to suit your every

mood. From comfortable cotton to

sexy satin.

SO IF YOU'VE GOT IT, FLAUNT IT

available to you coz

YOU'RE WORTH IT!!!

During the course of discussion students decided that

(a) They were selling two things - a material commodity and an idea. They agreed that it was more difficult to sell the idea.

(b) They were drawing on the discourse of changing gender relations as well as what they called the discourse of South African crime, this represented most clearly in the Material Processes 'highjacked' and 'stolen'. These discourses formed part of the explanatory domain of the text, which they explicitly noted.

(c) The general tenor of the advert was intended to be confrontational and somewhat hostile and so it was important to choose 'strong' Material Processes, ones which 'show that the women are in charge'. Criminal discourse served this purpose well.

(d) The interpersonal we/they dichotomy emphasised this communal challenge further as did the textual Theme 'now' which, to them, gave a strong indication of immanent 'takeover'.

(e) The deliberate ambiguity and sexual innuendo of 'to get into' built on what one student described as the 'invasive' nature of the text.

It was in this production of text that students' consolidation of understanding was most evident. This is significant because it is such understanding which can be applied in various ways in the workplace. SFG has the potential to assist students to develop such insights and this, above all, is why it should be actively encouraged and developed in our classrooms.

\section{CONCLUSION}

This course generated a wide range of pedagogical challenges. Within thirteen weeks, students were introduced to debates within media studies, to the central features of CDA and to key ideas in SFG and expected to develop at least the beginnings of a metalanguage that would facilitate their ability to analyse media texts. While no absolute claims can yet be made for the value of SFG to undergraduate students, it is clear from their analyses that they developed some understanding of Fairclough's model for CDA and that they had also acquired the basic metalanguage necessary for Hallidayan analysis. However, they had difficulty both with integrating CDA and SFG and with holistic textual analysis. They tended to work within one theoretical perspective or the other and were most adept with the interpretation and the production of discrete structures in the context of guided analysis. This often resulted in a mechanistic approach which emphasised the linguistic structure at the expense of the social purpose and context. Indeed, explicit links between analyses and the social nature of text were notably absent. 
Given the time constraints, it is possible to argue that CDA could give way to a more concentrated focus on SFG to allow more time for analysis of whole texts. This, however, is almost a contradiction in terms because it is precisely the critical framework which provides a context for a broad analysis which is both socially and linguistically grounded and gives students the necessary platform from which to build. CDA and SFG are mutually enriching and the course would be impoverished if either were excluded. Time constraints remain a challenge but it is nevertheless possible to make some important shifts. In future, the social nature of text will be constantly highlighted, similar aspects of CDA and SFG will be more frequently and explicitly mapped onto each other and exercises will be based on whole texts rather than sentences. There will be a constant process of reintegration after each new linguistic structure has been introduced and an additional practical period will be included to provide students with the opportunities for additional application.

Most importantly, more time will be allocated to the production of a range of texts, this to encourage the articulation of the linguistic process and choices involved and to make more explicit links with potential workplaces. This implies that the components of the course will be differently weighted, with less time allocated to CDA and the interpretation of text and more to its production.

As part of her evaluation of the course, one student said, 'I really enjoyed this course because I have never seen the real purpose of grammar before. Now I know how relevant it is but I still feel nervous about analysing difficult, long texts.' Her comment encapsulates the ongoing tension in the course. The achievement of better balance, integration and more frequent and holistic application remains the central challenge a challenge which, the evidence suggests, is well worth pursuing.

\section{REFERENCES}

BHATIA, VJ. 1993. Analysing genre: language use in professional settings. London: Longman.

BUTT, D, R FAHEY, S SPINKS \& C YALLOP. 2000. Using functional grammar: an explorer's guide. Macquarie University: Clarendon Printing.

CARTER, R (Ed.). 1990. Knowledge about language and the curriculum: the LINC reader. London: Hodder and Stoughton.

CHOULIARAKI, L \& N FAIRCLOUGH. 1999. Discourse in late modernity: rethinking critical discourse analysis. Edinburgh: Edinburgh University Press.

FAIRCLOUGH, N. 1989. Language and power. London: Longman.

FAIRCLOUGH, N. 1995a. Media discourse. Cambridge: Polity Press.

FAIRCLOUGH, N. 1995b. Critical discourse analysis: the critical study of language. London: Longman.

FAIRCLOUGH, N. 1995c. Language and social change. Cambridge: Polity Press. 
FAIRCLOUGH, N \& R WODAK. 1997. Critical discourse analysis. In Van Dijk, T (Ed.), Discourse as social interaction. London: Sage Publications: 258-284.

FISKE, J. 1994. Media matters: everyday culture and political change. Minneapolis: University of Minnesota Press.

FOUCAULT, M. 1970. The order of discourse. In Young, R (Ed.), Untying the text: a poststructuralist reader. London: Routledge and Kegan Paul. pp. 48-78.

FOWLER, R, B HODGE, G KRESS, \& T TREW. 1979. Language and control. London: Routledge and Kegan Paul.

GEE, JP. 1996. Social linguistics and literacies: ideology in discourses. Second edition. London: The Falmer Press.

HALLIDAY, MAK. 1978. Language as social semiotic: the social interpretation of language and meaning. London: Edward Arnold.

HALLIDAY, MAK. 1985. An introduction to functional grammar. London: Edward Arnold.

HALLIDAY, MAK \& R HASAN. 1989. Language, context and text: aspects of language in a social-semiotic perspective. Second Edition. Oxford: Oxford University Press.

IVANIC, R. 1990. Critical language awareness in action. In Carter, R (Ed.), Knowledge about language and the curriculum: the LINC reader. London: Hodder and Stoughton. pp. 122-133.

JANKS, H. 1996. 1996: Why we still need critical language awareness in South Africa. Paper presented at the third Stellenbosch conference on linguistics for the language professions. pp. 19.

KRESS, G. 1985. Linguistic processes in sociocultural practice. Oxford: Oxford University Press.

KRESS, G \& T VAN LEEUWEN. 1996. Reading images: the grammar of visual design. London: Routledge

MILLS, S. 1997. Discourse. London: Routledge.

PENNYCOOK, A. 1994. The cultural politics of English as an international language. London: Longman.

PENNYCOOK, A. 1995. Incommensurable discourses? Applied linguistics. 15(2):115-138.

TAYLOR, L \& A WILLIS. 1999. Media studies: texts, institutions and audiences. Massachusetts: Blackwell

TOLSON, A. 1996. Mediations: text and discourse in media studies. London: Amold. 
VAN DIJK, TA. 1997. Discourse as interaction in society. In Van Dijk, TE (Ed.). 1997. Discourse as social interaction. London: Sage Publications

VAN DIJK, TA (Ed.). 1997. Discourse as social interaction. London: Sage Publications.

WEEDON, C. 1997. Feminist practice and poststructuralist theory. Second Edition. Oxford: Basil Blackwell.

\section{Biographical Note}

Jenny Clarence-Fincham teaches in Applied Language Studies at the School of Language Culture and Communication, University of Natal, Pietermaritzburg. She has taught Applied Language Studies at Natal University for twenty years and her special interests include critical discourse analysis, second language teaching methodology, systemic functional grammar and media studies. 


\section{Appendix A}

\section{Text A}

Now it's cold. A light wind is usually blowing. It's very solitary. Really deep, laboured, hard breathing is all you can hear in your oxygen mask. People are just pools of headlamp lights above you and below you, and you rest when you want to rest and you try to keep up. . .

The mist slowly parted and Everest reared head and shoulders above the backdrop of the world's greatest peaks. We whooped, screamed and danced like madmen at the first sighting of this magnificent mountain. Then we all promptly crumpled to the floor gasping and wheezing because of the altitude and associated lack of oxygen.

(Out there magazine, March 1999)

\section{Text B}

\section{STUDENT PROTEST AT UDW ENTERS ITS THIRD DAY}

A student protest against the deregistration of 540 of their colleagues entered its third day yesterday at the University of Durban Westville.

Members of the Public Order Policing Unit (POP) were called to campus on Tuesday when demonstrating protesters damaged windows, toppled buses, and disrupted lectures and tests. The POP stabilised the situation but remained on the campus.

About 600 students gathered on the campus yesterday and toyi-toyied and held meetings under the watchful eye of the police.
The students marched around the quiet campus and tried to renegotiate with campus management regarding the deregistration of the students.

University spokesman Kiru Naidoo said the SRC's call to boycott classes was regrettable but management upholds the rights of students to protest there.

Natal Witness 11 May 2000 